\title{
Subarachnoid haemorrhage due to intracranial vertebral artery dissection presenting with atypical cauda equina syndrome features: case report
}

\author{
Lloyd Steele ${ }^{1 *}$ (D) Muhammad Hasan Raza ${ }^{1}$, Richard Perry ${ }^{2}$, Neil Rane ${ }^{3}$ and Sophie J. Camp ${ }^{1}$
}

\begin{abstract}
Background: Failing to recognise the signs and symptoms of subarachnoid haemorrhage (SAH) causes diagnostic delay and may result in poorer outcomes. We report a rare case of SAH secondary to a vertebral artery dissection (VAD) that initially presented with cauda equina-like features, followed by symptoms more typical of SAH.

Case presentation: A 55-year-old man developed severe lower back pain after sudden movement. Over the next 5 days he developed paraesthesiaes in the feet, progressing to the torso gradually, and reported constipation and reduced sensation when passing urine. On day six he developed left facial palsy, and later gradual-onset headache and intermittent confusion.

Magnetic resonance imaging of the brain showed diffuse subarachnoid FLAIR hyperintensity, concerning for blood, including a focus of cortical/subcortical high signal in the left superior parietal lobule, which was confirmed by computed tomography. Digital subtraction angiography demonstrated a left VAD with a fusiform aneurysm.

Conclusion: We present a very rare case of intracranial VAD with SAH initially presenting with spinal symptoms. The majority of subsequent clinical features were consistent with a parietal focus of cortical subarachnoid blood, as observed on neuroimaging.
\end{abstract}

Keywords: Case report, Hypesthesia, Vertebral artery, Subarachnoid hemorrhage, Aneurysm, Dissecting, Headache, Facial nerve

\section{Background}

The reported rates of misdiagnosis of nontraumatic subarachnoid haemorrhage (SAH) in the literature have been significant $(5 \%,[1,2] 12-20 \%[3]$ and $13-43 \%[4])$. Whilst this is most common with lower acuity presentations, [1] initial misdiagnosis may later result in a catastrophic outcome [4].

In this case we describe a rare presentation of SAH secondary to vertebral artery dissection (VAD) that initially presented with spinal symptoms. Only two previous cases of intracranial VAD have been associated with spinal extension of SAH $[5,6]$.

\footnotetext{
* Correspondence: Lloyd.Steele@nhs.net

${ }^{1}$ Department of Neurosurgery, Charing Cross Hospital, Imperial College Healthcare NHS Trust, Fulham Palace Rd, Hammersmith, London W6 8RF, UK Full list of author information is available at the end of the article
}

\section{Case presentation}

A 55-year-old man developed severe lower back pain after heavy lifting. Over the next 5 days he experienced paraesthesiaes in the feet, progressing to the torso, and reduced sensation when passing urine. On day six he presented to hospital after waking and noticing a left facial droop. On presentation he also reported a 3 day history of constipation. There was no history of headache, neck stiffness, or trauma. He was a current smoker (15 cigarettes per day) and drank 70 units of alcohol per week. There was no significant past medical history and he used no regular medications.

His vital signs on admission revealed hypertension (blood pressure $160 / 92 \mathrm{mmHg}$ ) and tachycardia (heart rate 103 beats per minute), but were otherwise within normal limits. Glasgow coma scale was 15 . On examination there was 
left-sided facial weakness (House-Brackmann grade IV) with no forehead sparing (lower motor neurone pattern). The remainder of the cranial nerve examination was normal. Tone was normal and there was no clonus. Pyramidal drift was present in the right upper limb, but muscle power was Medical Research Council grade 5/5 in all muscle groups. Deep tendon reflexes were elicited (normal) apart the ankle reflex, which was absent bilaterally. The plantar response was downgoing bilaterally. Light touch and pain sensation were reduced, but present, to T6 bilaterally most notably across L4-S1 and S3-S4 (saddle anaesthesia) and vibration sense was reduced to the ankle bilaterally. Gait was unsteady and the patient was unable to tandem walk. There was no limb ataxia. Anal tone was normal, there was no significant residual volume on urinary catheterisation, and the patient could feel a catheter tug.

The presentation of lower back pain with bladder and bowel symptoms led to the emergency department (ED) team making an initial diagnosis of Bell's palsy and cauda equina syndrome and arranging magnetic resonance imaging (MRI) of the lumbo-sacral spine. This demonstrated only a small disc protrusion at L5/S1 abutting the transiting right S1 root (Fig. 1).

Due to the facial nerve palsy, imaging for a central cause was performed. MRI of the brain showed diffuse subarachnoid fluid-attenuated inversion recovery (FLAIR) hyperintensity concerning for blood, including in the basal cistern and Sylvian fissures. There was also a focus of cortical/subcortical high signal in the left superior parietal lobule (Fig. 2). MRI of the cervico-thoracic spine did not demonstrate SAH. The SAH was confirmed by computed tomography $(\mathrm{CT})$. To investigate for a cause, $\mathrm{CT}$ angiography (CTA) was performed which demonstrated some prominence of the left-sided parafalcine cortical vessels. Digital subtraction angiography (DSA) demonstrated a left VAD (Fig. 3), with a dissection flap within a fusiform dilatation of the left intradural vertebral artery.

When SAH was confirmed, nimodipine $60 \mathrm{mg}$ 4-hourly for 21 days, analgesia, euvolaemia and bed rest were commenced. Given the facial palsy, eye protection was ensured. The patient was discussed at the neurovascular multi-disciplinary team (MDT) meeting where conservative management of the VAD was advocated based on a delayed and atypical presentation, treatment risking vessel occlusion, and patient choice.

The patient was monitored on the Intensive Care Unit following the DSA, and was later transferred to the neurosurgical ward. During the admission the patient had headache, intermittent confusion, and poor memory. Repeat CTA at 2 weeks showed stable appearances of the dissection and the patient was discharged with outpatient follow-up,

Clinic review at 12 weeks revealed the patient had returned to full-time work with resolution of most symptoms, apart from intermittent paraesthesiaes in the

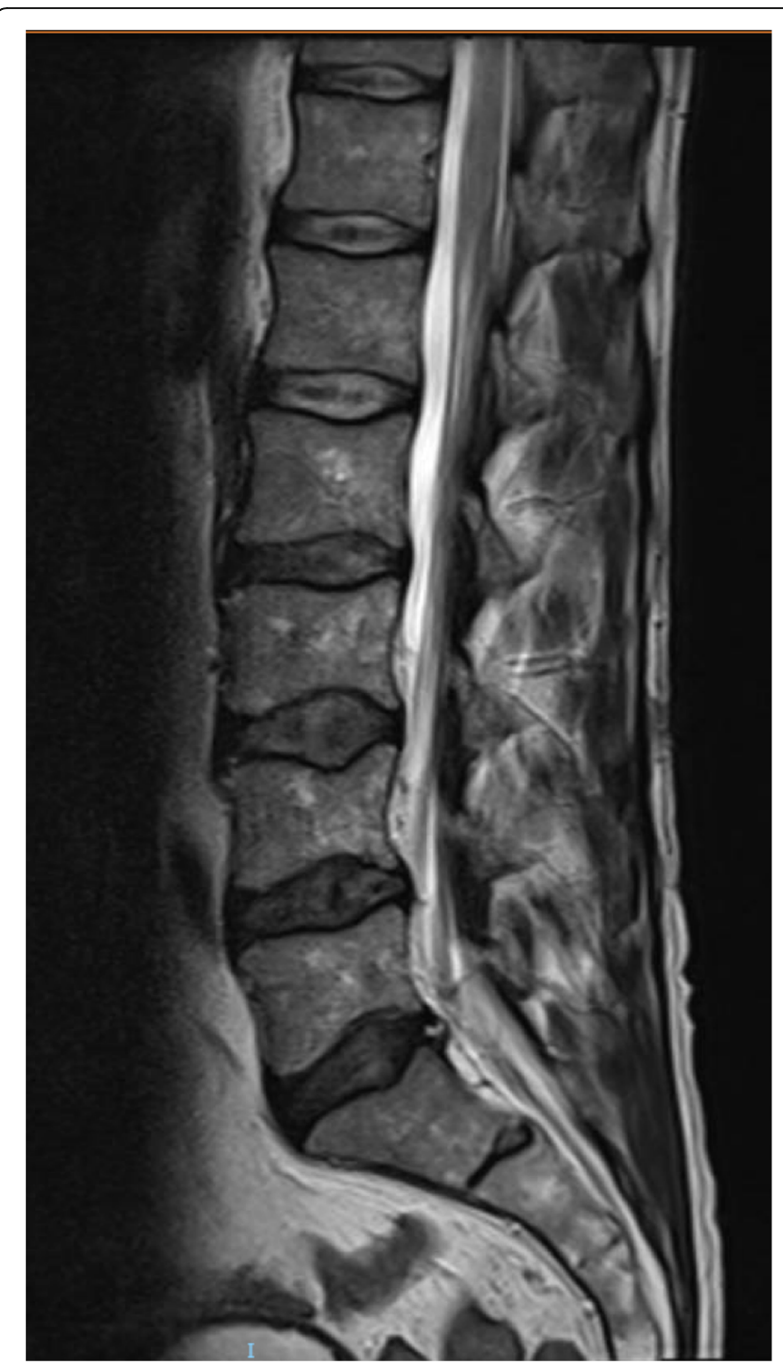

Fig. 1 Magnetic resonance imaging of the lumbo-sacral spine showing no significant spinal cord compression

toes. Cranial nerves were intact with full recovery of facial nerve function, and peripheral neurological examination was normal. Magnetic resonance angiography (MRA) at 12 weeks showed stable appearances of the dissecting aneurysm, with no new parenchymal abnormalities nor other adverse features. Repeat MRA at 9 months demonstrated no change in the aneurysm. (Fig. 4) Imaging surveillance is to continue, with repeat MRA planned after a further 6 months.

\section{Discussion}

We report a rare cause of VAD with SAH that initially presented with predominantly spinal symptoms. The presentation of SAH with cauda-equina features has been reported very rarely with SAH. In one case, arachnoiditis was the reported cause [7]. However, this is a delayed complication, which imaging excluded this in our case [8]. An alternative explanation is spinal cord 

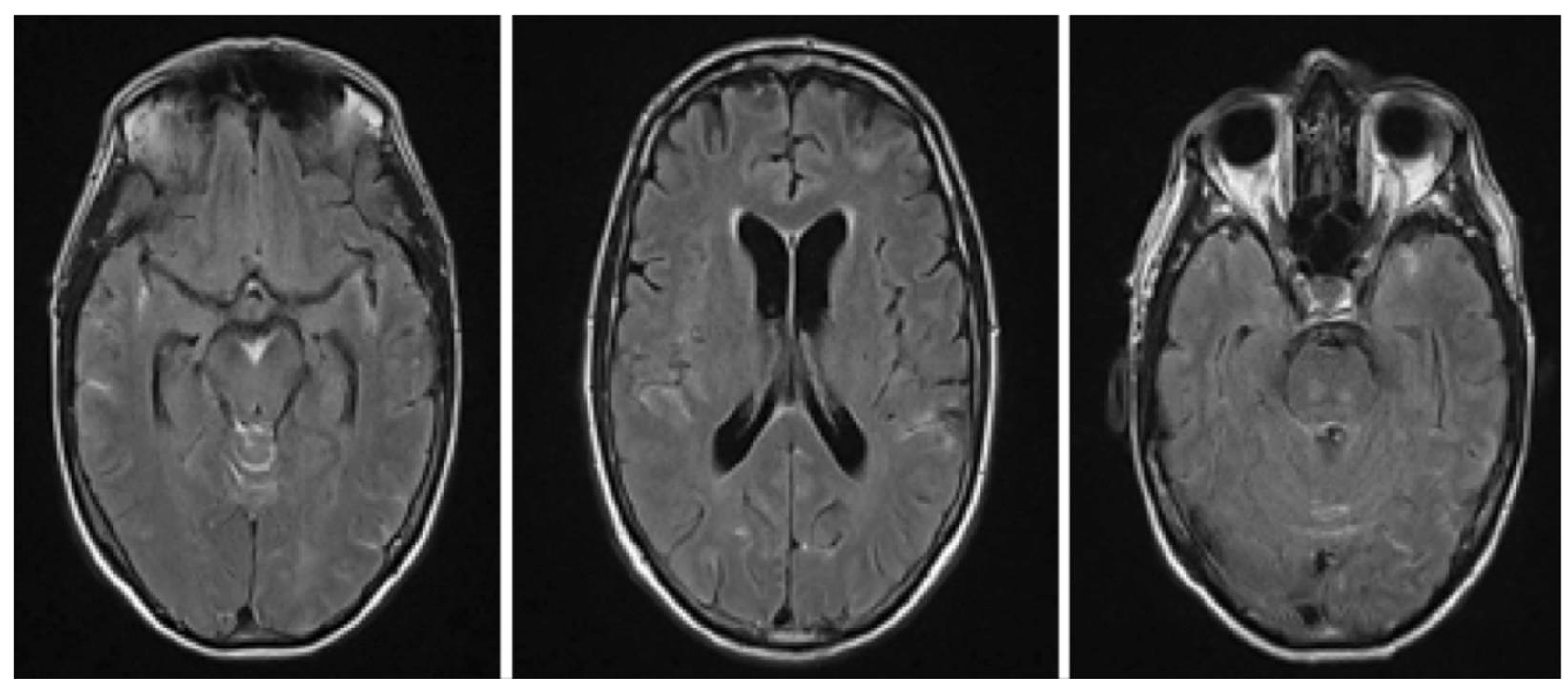

Fig. 2 Magnetic resonance images of the brain showing diffuse subarachnoid fluid-attenuated inversion recovery (FLAIR) hyperintensity concerning for blood within the parafalcine, left frontal, bilateral occipital and bilateral temporal sulcal spaces, Sylvian fissures and the basal cistern. It also showed a focus of cortical/subcortical high signal in the left superior parietal lobule. No meningeal or parenchymal enhancement was demonstrated

ischaemia, which is very rarely associated with SAH [9, 10]. With cord ischaemia, image findings are delayed, [11] which has also been reported when cord infarction is due VAD, [12] and thus repeat spinal imaging would have been valuable in our case. An alternative consideration for cauda-equina like features is spinal $\mathrm{SAH}$, which can cause back pain, sensory disturbance, and sphincter disturbance [13]. Very rarely, intracranial VAD has been associated with spinal extension of SAH $[5,6]$. Although MRI in our case did not suggest a spinal SAH, MRI is not perfectly sensitive for spinal SAH, and in one case report MRI imaging of the spine was initially normal [14]. Moreover, the intensity of back pain in patients with SAH often correlates with the amount of blood in the lumbo-sacral subarachnoid space, [9] and the back pain had largely resolved by the time of admission in this case.

The initial absence of headache or neck stiffness in our case is unclear. It may reflect a combination of severe pain elsewhere (distraction) and confusion. It could also reflect that the headache developed due to redistribution of blood products. In a series of 8 patients with spinal SAH, $25 \%$ also had cortical/convexal SAH (cSAH) [13]. In our case, a convexal/subconvexal focus of blood affecting the parietal lobule was seen, which could explain why the patient developed headache, facial nerve


Fig. 3 Digital subtraction angiography revealing fusiform dilatation of the left intradural vertebral artery (white arrow) 


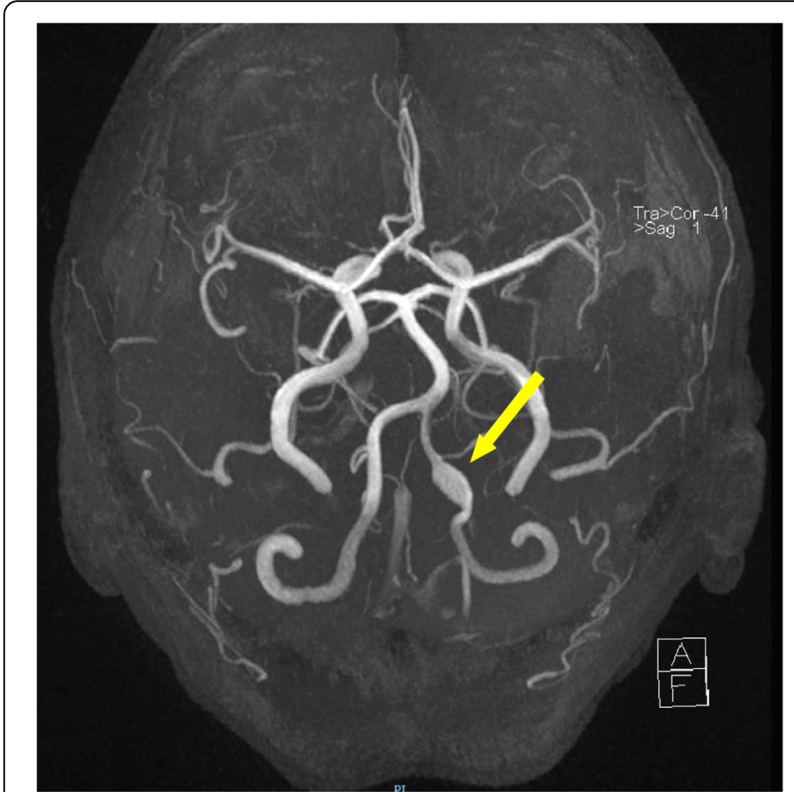

Fig. 4 Magnetic resonance angiography 9-months post-presentation demonstrating stable appearances of the dissection aneurysm (yellow arrow)

palsy, and confusion. In various case series of cSAH, reported features have included focal and transient motor and/or sensory symptoms (42-73\%), including facial nerve palsy and pronator drift $[15,16]$; headache $(18-65 \%)$; and confusion $(9.8 \%)$ [17-20]. Although cSAH by definition spares the basal cistern and Sylvian fissures (which our case does not), descriptions of cSAH have been made even when these regions are not spared [21-23]. Alternative considerations for facial nerve palsy are compression by the aneurysm (which imaging did not suggest in our case) and vascular spasm disturbing the blood supply of the facial nucleus $[24,25]$.

There is no consensus for the treatment of intracranial dissections, [26] but treatment is usually performed because of the high risk of rebleeding within the first days of the event [27]. Endovascular techniques have been the mainstay of treatment, as these aneurysms are typically inaccessible surgically [28]. Conservative management with follow-up and blood pressure control is also an option, which is a decision determined by the assessment of risk for a poor outcome (such as poor neurological status on admission, rebleeding, and lesions with a pearl-and-string-structure) and the risk and feasibility of intervention [29]. Factors influencing our decision were the delayed and atypical presentation, the good neurological status on admission, patient aversion to operative management, and the feasibility of intervention - with the location of the fusiform aneurysm necessitating occlusion of the posterior inferior cerebellar artery. Flow diversion was also an off-label option, with limited data suggesting comparable outcomes in the long-term to conventional techniques, but with potentially greater shortterm complications and the need for dual antiplatelet therapy [30].

\section{Conclusions}

This case details a rare presentation of intracranial VAD with spinal symptoms, prior to the development of features that were more suggestive of a parietal focus of cortical blood. This case highlights the wide range of presenting features of SAH and the need for the consideration of SAH for sudden-onset spinal symptoms.

\section{Abbreviations \\ CSAH: cortical/convexal subarachnoid haemorrhage; CT: Computed tomography; CTA: Computed tomography angiography; DSA: Digital subtraction angiography; FLAIR: Fluid-attenuated inversion recovery; MDT: Multidisciplinary team; MRA: Magnetic resonance angiography; MRI: Magnetic resonance imaging; SAH: Subarachnoid haemorrhage; VAD: Vertebral artery dissection}

\section{Acknowledgements}

Not applicable.

\section{Authors' contributions}

$L S, M H R, R P, N R$, and SJC were involved in the clinical care of the patient. LS drafted the manuscript and MHR, RP, NR, and SJC provided critical review. All authors read and approved the final manuscript.

\section{Authors' information}

LS is a Core Medical Trainee.

MHR is a Specialist Registrar in Neurosurgery.

$\mathrm{RP}$ is a Consultant in Neurology.

SJC is a Consultant in Neurosurgery.

Funding

No funding for the study.

Availability of data and materials

Not applicable.

Ethics approval and consent to participate Not applicable.

\section{Consent for publication}

Informed written consent was obtained from the indexed patient.

\section{Competing interests}

The authors declare that they have no competing interests.

\section{Author details}

${ }^{1}$ Department of Neurosurgery, Charing Cross Hospital, Imperial College Healthcare NHS Trust, Fulham Palace Rd, Hammersmith, London W6 8RF, UK. ${ }^{2}$ Department of Neurology, Charing Cross Hospital, Imperial College Healthcare NHS Trust, London, UK. ${ }^{3}$ Department of Interventional Neuroradiology, Charing Cross Hospital, Imperial College Healthcare NHS Trust, London, UK.

Received: 23 November 2018 Accepted: 6 October 2019

Published online: 30 October 2019

\section{References}

1. Vermeulen MJ, Schull MJ. Missed diagnosis of subarachnoid hemorrhage in the emergency department. Stroke. 2007;38(4):1216-21.

2. Edlow JA. Diagnosis of subarachnoid hemorrhage: are we doing better? Stroke. 2007;38(4):1129-31.

3. Kowalski RG, Claassen J, Kreiter KT, Bates JE, Ostapkovich ND, Connolly ES, Mayer SA. Initial misdiagnosis and outcome after subarachnoid hemorrhage. JAMA. 2004;291(7):866-9. 
4. Mayor S. Earlier diagnosis is needed to reduce deaths and disability from aneurysmal subarachnoid haemorrhage. BMJ. 2013;347:f6925.

5. Ovali GY, Adam G, Cinar C, Bozkaya H, Calli C, Kitis O, Oran I. Symptomatic spinal migration of subarachnoid hemorrhage due to ruptured Intradural vertebral artery aneurysm. J Neuroimaging. 2015;25(4):668-70.

6. Neto L, Moura Guedes M, Campos J. Spinal subarachnoid hemorrhage mimicking an acute abdomen. Neuroradiol J. 2012;25(2):217-21.

7. Whetstone KE, Crane DA. Cauda equina syndrome resulting from lumbar arachnoiditis after intracranial subarachnoid hemorrhage: a case report. PM R. 2013;5(6):539-41.

8. Atallah E, Dang S, Rahm S, Feghali J, Nohra C, Tjoumakaris S, Rosenwasser $\mathrm{RH}$, Zarzour H, Herial N, Gooch MR, et al. Rare case of diffuse spinal arachnoiditis following a complicated vertebral artery dissection. J Clin Neurosci. 2018;52:132-4.

9. Krishna V, Lazaridis C, Ellegala D, Glazier S, Kindy M, Spampinato M, Chalela JA. Spinal cord infarction associated with subarachnoid hemorrhage. Clin Neurol Neurosurg. 2012;114(7):1030-2.

10. Kashiwagi S, Tsuchida E, Shiroyama Y, Ito H, Yamashita T. Paraplegia due to a ruptured aneurysm of the distal posterior inferior cerebellar artery. J Neurol Neurosurg Psychiatry. 1992;55(9):836-7.

11. Montalvo M, Bayer A, Azher I, Knopf L, Yaghi S. Spinal cord infarction because of spontaneous vertebral artery dissection. Stroke. 2018;49(11):e314-7.

12. Ginos J, McNally S, Cortez M, Quigley E, Shah LM. Vertebral artery dissection and cord infarction - an uncommon cause of Brown-Sequard and Horner syndromes. Cureus. 2015;7(8):e308.

13. Yost MD, Rabinstein AA. Spontaneous spinal subarachnoid hemorrhage: presentation and outcome. J Stroke Cerebrovasc Dis. 2018;27(10):2792.

14. Sasaji T, Shinagawa K, Matsuya S. Spontaneous thoracic spinal subarachnoid hemorrhage diagnosed with brain computed tomography. Tohoku J Exp Med. 2013;231(2):139-44.

15. Fukuma K, Ihara M, Tanaka T, Morita Y, Toyoda K, Nagatsuka K. Intracranial cerebral artery dissection of anterior circulation as a cause of convexity subarachnoid hemorrhage. Cerebrovasc Dis. 2015:40(1-2):45-51.

16. Mao DQ, Addess D, Valsamis H. A report of nontraumatic cortical subarachnoid hemorrhage and subsequent management. Future Neurol. 2016;11(4):231-5.

17. Renou P, Tourdias T, Fleury O, Debruxelles S, Rouanet F, Sibon I. Atraumatic nonaneurysmal sulcal subarachnoid hemorrhages: a diagnostic workup based on a case series. Cerebrovasc Dis. 2012:34(2):147-52.

18. Chertcoff A, Bandeo L, Pantiu F, Cejas LL, Pacha S, Roca CU, Pardal MF, Reisin R, Bonardo P. Convexity subarachnoid hemorrhage: clinical features and etiology of an Argentinian cohort. Arq Neuropsiquiatr. 2017;75(12):858-61.

19. Beitzke M, Gattringer T, Enzinger C, Wagner G, Niederkorn K, Fazekas F. Clinical presentation, etiology, and long-term prognosis in patients with nontraumatic convexal subarachnoid hemorrhage. Stroke. 2011;42(11):3055-60.

20. Khurram A, Kleinig T, Leyden J. Clinical associations and causes of convexity subarachnoid hemorrhage. Stroke. 2014;45(4):1151-3.

21. Iyer RS, Ramalingam RTC, Akhtar S, Muthukalathi K. Perimesencephalic and sulcal subarachnoid haemorrhage: an interesting presentation of posterior reversible encephalopathy syndrome. BMJ Case Rep. 2018;2018:bcr-2017.

22. Okar S, Arat A, Arsava EM, Peker A, Berker M, Topcuoglu MA. Can convexity subarachnoid hemorrhage be caused by rupture of a Saccular aneurysm? J Vasc Interv Neurol. 2018;10(2):1-3.

23. Bandeo L, Rausch A, Saucedo M, Chertcoff A, Cejas LL, Roca CU, Pacha S, Pardal MF, Reisin R, Bonardo P. Convexity subarachnoid hemorrhage secondary to Adalidumab in a patient with ulcerative colitis. J Vasc Interv Neurol. 2018;10(2):62-4.

24. Kurokawa R, Saito R, Nakamura Y, Kagami H, Ichikizaki K. Ruptured vertebral artery-posterior inferior cerebellar artery aneurysm associated with facial nerve paresis successfully treated with interlocking detachable coils--case report. Neurol Med Chir (Tokyo). 1999:39(12):863-6.

25. Wen HJ, Yang JS, Li YQ. Transient unilateral facial paralysis induced by perimesencephalic non-aneurysmal subarachnoid hemorrhage: a case report and review of the literature. Exp Ther Med. 2015;10(4):1541-3.

26. Debette S, Compter A, Labeyrie MA, Uyttenboogaart M, Metso TM, Majersik J, Goeggel-Simonetti B, Engelter ST, Pezzini A, Bijlenga P, et al. Epidemiology, pathophysiology, diagnosis, and management of intracranial artery dissection. Lancet Neurol. 2015;14(6):640-54.

27. Daou B, Hammer C, Chalouhi N, Starke RM, Jabbour P, Rosenwasser RH, Tjoumakaris S. Dissecting pseudoaneurysms: predictors of symptom occurrence, enlargement, clinical outcome, and treatment. J Neurosurg. 2016:125(4):936-42.

28. Wallace AN, CreveCoeur TS, Grossberg JA, Kamran M, Osbun JW, Delgado Almandoz JE, Kayan Y, Cross DT, Moran CJ. Impact of aneurysm morphology on safety and effectiveness of flow diverter treatment of vertebrobasilar aneurysms. J Neuroradiol. 2019;46(6):401-10.

29. Yamada M, Kitahara T, Kurata A, Fujii K, Miyasaka Y. Intracranial vertebral artery dissection with subarachnoid hemorrhage: clinical characteristics and outcomes in conservatively treated patients. J Neurosurg. 2004;101(1):25-30

30. Dmytriw AA, Phan K, Moore JM, Pereira VM, Krings T, Thomas AJ. On flow diversion: the changing landscape of Intracerebral aneurysm management. AJNR Am J Neuroradiol. 2019;40(4):591-600

\section{Publisher's Note}

Springer Nature remains neutral with regard to jurisdictional claims in published maps and institutional affiliations.
Ready to submit your research? Choose BMC and benefit from:

- fast, convenient online submission

- thorough peer review by experienced researchers in your field

- rapid publication on acceptance

- support for research data, including large and complex data types

- gold Open Access which fosters wider collaboration and increased citations

- maximum visibility for your research: over $100 \mathrm{M}$ website views per year

At $\mathrm{BMC}$, research is always in progress.

Learn more biomedcentral.com/submissions 